\title{
Auditory Brainstem Implantation Improves Speech Recognition in Neurofibromatosis Type II Patients
}

\author{
Cordula Matthies $^{a} \quad$ Stefan Brill ${ }^{b}$ Kimitaka Kaga ${ }^{c}$ Akio Morita ${ }^{d}$ \\ Kozo Kumakawa ${ }^{\text {e Henryk Skarzynski }{ }^{f} \text { Andre Claassen }}{ }^{g}$ Yau Hui ${ }^{\text {h }}$ \\ Charlotte Chiongi Joachim Müller ${ }^{j}$ Robert Behrk
}

\begin{abstract}
Departments of a Neurosurgery and b Otorhinolaryngology, University of Würzburg, Würzburg, Germany; ${ }^{C}$ National Institute of Sensory Organs, National Tokyo Medical Center, ${ }^{d}$ Department of Neurology and Stroke Unit, NTT Medical Center, and e Department of Otolaryngology, Toranomon

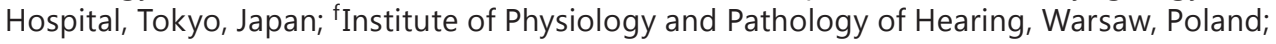
gDepartment of Otorhinolaryngology, Free State University, Bloemfontein, South Africa; hDivision of Otorhinolaryngology Head and Neck Surgery, Department of Surgery, The University of Hong Kong Medical Centre, Queen Mary Hospital, Hong Kong, SAR, China; i University of the Philippines Manila, Philippine National Ear Institution, NIH, Manila, Philippines; ${ }^{j}$ Klinik und Poliklinik für Hals-Nasen-Ohren-Heilkunde, Ludwig-Maximilians-University, Munich, and ${ }^{k}$ Department of Neurosurgery, Klinikum Fulda gAG, Fulda, Germany
\end{abstract}

\section{Key Words}

Acoustic neuroma - Auditory brainstem implant - Nonauditory side effects · Open-set sentence recognition - Subjective benefits - Vestibular schwannoma

\begin{abstract}
This prospective study aimed to determine speech understanding in neurofibromatosis type II (NF2) patients following implantation of a MED-EL COMBI 40+ auditory brainstem implant (ABI). Patients $(n=32)$ were enrolled postsurgically. Nonauditory side effects were evaluated at fitting and audiological performance was determined using the Sound Effects Recognition Test (SERT), Monosyllable-Trochee-Polysyllable (MTP) test and open-set sentence tests. Subjective benefits were determined by questionnaire. ABI activation was documented in 27 patients, 2 patients were too ill for testing and 3 patients were without any auditory perception. SERT and MTP outcomes under auditory-only conditions improved significantly between first fitting and 12-month follow-up. Open-set sentence recognition improved from $5 \%$ at first fitting to $37 \%$ after 12 months. The number of active electrodes had no significant effect on performance. All questionnaire respondents were 'satisfied' to 'very satisfied' with their ABI. An ABI is an effective treatment option in NF2 patients with the potential to provide open-set speech recognition and subjective benefits. To our knowledge, the data presented herein is exceptional in terms of the open-set speech perception achieved in NF2 patients.
\end{abstract}




\section{Introduction}

Neurofibromatosis type II (NF2) typically leads to a clinical picture dominated by neurological symptoms caused by the development of multiple benign spinal and brain tumors (Schwann cell tumors) [1]. The hallmark of NF2 is the development of bilateral vestibular schwannomas. However, unilateral vestibular schwannomas, a family history of NF2, or any two of meningioma, glioma, neurofibroma, schwannoma or posterior subcapsular opacities are also diagnostic criteria for NF2 [2].

Vestibular schwannomas involve the internal auditory canal or cerebellopontine angle and frequently result in severe disability and reduced life expectancy. Complete loss of hearing is common in the majority of bilaterally affected patients due to the destruction of the auditory nerve, usually resulting either from tumor growth or from treatment (by surgical tumor removal or radiosurgery). After surgical treatment of the tumor the hearing preservation of patients, who showed useful preoperative hearing, ranges from 32 to $88 \%$ [3-6]. Patients with deafness and preserved function of the cochlear nerve are good candidates for cochlear implantation $[7,8]$. However, in patients with complete hearing loss, following nerve degeneration or nerve loss by tumor destruction, an auditory brainstem implant (ABI) represents the only remaining therapeutic option to provide patients with auditory input [9-13].

Several studies indicate that ABIs are effective and safe in providing useful auditory sensations in most patients with NF2 who would otherwise be totally deaf $[9,14-21]$. However, only a minority of the patients in the aforementioned studies achieved open-set speech discrimination and the speech recognition of individuals with an ABI varied considerably; most patients use their ABI to facilitate lip-reading and can only recognize environmental sounds [9, 15-19, 22]. Importantly, even those with strongly limited speech recognition reported being very satisfied with their implant, showing that NF2 patients can gain remarkable objective and subjective benefits from $A B I$ use [18].

Another factor contributing to the performance of an ABI are nonauditory side effects. Typically, nonauditory side effects are produced via inadvertent stimulation of the cerebellar flocculus, the cerebellar peduncle, the long sensory tracts or the facial nerve. It is not unusual for NF2 patients with an ABI to experience nonauditory sensations [23]. Up to 42\% of users experience them [24, 25] and almost all of these nonauditory effects are benign, but they cause considerable discomfort to the individual [23]. Nonauditory side effects are usually managed by selecting the configuration of the electrodes [26], i.e. programming out the stimulus. In multichannel ABIs different sites of electrode stimulation can generate different pitch percepts [27]. Therefore, changes in the frequency spectrum of sounds can be coded for by changes in electrode activation [27]. Consequently, deactivation of electrodes due to nonauditory sensations can potentially affect the performance seen in patients fitted with an ABI. Although reports indicate that the number of functional electrodes affects the performance of speech recognition tests $[19,28]$, opinions regarding the existence of a correlation between the number of active electrodes and patient performance remain divided.

This study aimed to determine speech understanding capabilities over time in NF2 patients following implantation of an ABI. In particular, this paper evaluated open-set speech understanding and subjective benefits in NF2 patients with an ABI, who experience some auditory sensation, over a 1-year postactivation period. In addition, the frequency and consequences of nonauditory side effects were assessed. 
Matthies et al.: Auditory Brainstem Implantation Improves Speech Recognition in

Table 1. Subject demographics

\begin{tabular}{|c|c|c|c|c|c|c|c|c|c|}
\hline \multirow{2}{*}{$\begin{array}{l}\text { Subject } \\
\text { ID }\end{array}$} & \multicolumn{2}{|c|}{ Age at implantation } & \multirow[t]{2}{*}{ Gender } & \multirow{2}{*}{$\begin{array}{l}\text { Side } \\
\text { implanted }\end{array}$} & \multicolumn{5}{|c|}{ Number of active electrodes } \\
\hline & years & months & & & $\begin{array}{l}\text { first } \\
\text { fitting }\end{array}$ & $\begin{array}{l}1 \\
\text { month }\end{array}$ & $\begin{array}{l}3 \\
\text { months }\end{array}$ & $\begin{array}{l}6 \\
\text { months }\end{array}$ & $\begin{array}{l}12 \\
\text { months }\end{array}$ \\
\hline 1 & 41 & 8 & M & $\mathrm{R}$ & 10 & 10 & - & - & - \\
\hline 2 & 34 & 11 & $\mathrm{~F}$ & $\mathrm{~L}$ & 10 & 10 & 11 & 10 & - \\
\hline 3 & 42 & 3 & M & $\mathrm{R}$ & 5 & 4 & 5 & 5 & 2 \\
\hline 4 & 63 & 7 & M & $\mathrm{R}$ & 10 & 9 & 12 & 12 & 12 \\
\hline 5 & 49 & 10 & M & $\mathrm{R}$ & 12 & - & 12 & 12 & 12 \\
\hline $6^{1}$ & 42 & 4 & $\mathrm{~F}$ & $\mathrm{~L}$ & \multicolumn{5}{|c|}{ too sick to test } \\
\hline 7 & 36 & 5 & M & $\mathrm{L}$ & 7 & 8 & - & 9 & 9 \\
\hline 8 & 22 & 7 & M & $\mathrm{L}$ & 7 & - & 8 & 8 & 8 \\
\hline $9^{1}$ & 48 & 4 & $\mathrm{~F}$ & $\mathrm{R}$ & \multicolumn{5}{|c|}{ nonuser } \\
\hline 10 & 45 & 12 & $\mathrm{~F}$ & $\mathrm{R}$ & 12 & 12 & 9 & 8 & 8 \\
\hline 11 & 23 & 1 & M & $\mathrm{R}$ & - & 7 & 7 & 7 & 7 \\
\hline 12 & 35 & 12 & M & $\mathrm{R}$ & 7 & 7 & 7 & 7 & 7 \\
\hline 13 & 54 & 1 & $\mathrm{~F}$ & $\mathrm{R}$ & 12 & 12 & 12 & 12 & 12 \\
\hline 14 & 27 & 7 & $\mathrm{~F}$ & $\mathrm{~L}$ & 9 & 10 & - & 9 & 9 \\
\hline 15 & 25 & 11 & $\mathrm{~F}$ & $\mathrm{R}$ & 7 & 7 & 7 & 12 & 12 \\
\hline 16 & 19 & 3 & $\mathrm{~F}$ & $\mathrm{R}$ & 8 & 8 & 8 & 8 & 7 \\
\hline $17^{1}$ & 40 & 12 & $\mathrm{~F}$ & $\mathrm{R}$ & \multicolumn{5}{|c|}{ nonuser } \\
\hline 18 & 39 & 12 & M & $\mathrm{L}$ & 12 & 8 & 10 & 10 & 10 \\
\hline $19^{1}$ & 40 & 3 & $\mathrm{~F}$ & $\mathrm{~L}$ & \multicolumn{5}{|c|}{ too sick to test } \\
\hline 20 & 51 & 1 & $\mathrm{~F}$ & $\mathrm{~L}$ & 8 & 8 & 6 & 6 & 6 \\
\hline $21^{1}$ & 30 & 2 & M & $\mathrm{L}$ & \multicolumn{5}{|c|}{ nonuser } \\
\hline 22 & 21 & 5 & $\mathrm{~F}$ & $\mathrm{R}$ & 12 & 12 & 12 & - & - \\
\hline 23 & 41 & 9 & $\mathrm{~F}$ & $\mathrm{R}$ & 7 & 7 & - & - & - \\
\hline 24 & 66 & 11 & M & $\mathrm{R}$ & 10 & 9 & 9 & 9 & 9 \\
\hline 25 & 39 & 7 & M & $\mathrm{R}$ & 8 & 8 & - & - & - \\
\hline 26 & 43 & 4 & $\mathrm{~F}$ & $\mathrm{~L}$ & 6 & 6 & 6 & 6 & - \\
\hline 27 & 42 & 10 & M & bilateral & 6 & 5 & 5 & 5 & 5 \\
\hline 28 & 31 & 8 & M & $\mathrm{L}$ & - & - & - & - & - \\
\hline 29 & 42 & 2 & M & $\mathrm{R}$ & - & - & - & - & - \\
\hline $30^{2}$ & 33 & 6 & M & $\mathrm{R}$ & - & - & - & - & - \\
\hline $31^{2}$ & 26 & 8 & M & $\mathrm{L}$ & - & 7 & 7 & 7 & 7 \\
\hline 32 & 25 & 7 & $\mathrm{~F}$ & $\mathrm{R}$ & 8 & 8 & 8 & 8 & 8 \\
\hline
\end{tabular}

${ }^{1}$ Not included in data analysis. ${ }^{2}$ Revision cases.

\section{Materials and Methods}

\section{Patients and Inclusion Criteria}

Between April 2001 and July 2009, 32 patients who received a MED-EL COMBI 40+ ABI were enrolled postsurgically in this prospective multicenter study; 16 patients were treated at Würzburg (University of Würzburg, Würzburg, Germany), while the remainder were treated at 6 other centers. The mean age at implantation was 38.4 years (range: 19.0-66.1 years). Individual subject data are shown in table 1. For inclusion in this study, subjects were 15 years or older and diagnosed with NF2. All patients gave written informed consent.

All patients were implanted using the surgical procedure as described by Matthies et al. [16] (2000), Behr et al. [18] (2007) and Jackson et al. [22] (2002); 6 participants received the MED-EL COMBI 40+ and 26 the $\mathrm{ABI}$. The $\mathrm{ABI}$ is a development of the COMBI $40+$ offering an electronic platform, which allows a maximum stimulation rate of 50.760 compared to 18.180 pulses/second, which was possible with the COMBI 40+. Besides the electronics there is no difference between the 2 implants. Both feature a ceramic housing, offer the CIS+ speech-coding strategy [29], and comprise an electrode carrier with 13 (12 stimulation and 1 
reference) platinum contacts partially embedded in a preshaped flat silicone paddle [18, 22]. In addition, the ABI electrode features a polyester mesh to increase the stability of the electrode array on the surface of the cochlear nucleus.

At the time of enrolment all subjects showed acceptable general health and mental stability. However, at follow-up 5 subjects could not be included in the study due to poor health, which prevented them from performing any tests (subjects 6 and 19), or they were excluded because they did not experience any auditory sensation (subjects 9, 17 and 21). Subjects 27 and 30 underwent ABI implantation a number of years earlier without success. Subject 27 was bilaterally implanted as a nonuser in the left ear, and was tested with the active right implant. Subject 26 had prior ABI experience; however, the ABI lost function following tumor regrowth. Likewise, subject 31 had prior ABI experience; however, trauma resulting in an implant defect led to implantation of a new device on the same side.

\section{Device Fitting}

All patients were fitted with the TEMPO+ BTE speech processor. In general, initial stimulation took place 6-8 weeks after surgery and was performed during a 3-day inpatient hospitalization. In some cases an extended rehabilitation period after tumor removal was required and led to delayed implant activation.

First fitting was performed in a monitored environment such as an Intensive Care Unit. Pulse oximetry, continuous echocardiography and noninvasive blood pressure were monitored during the fitting process. Emergency resuscitation equipment and drugs were available and an Advanced Cardiac Life Support certified individual was present. Activation commenced with stimulation of individual electrodes. Patients were instructed to report any auditory and nonauditory sensations. Electrodes with clear auditory percept and no or negligible nonauditory side effects were selected for an initial program.

Following 1-2 days of listening experience and refinement of the initial program the first assessment of performance was conducted. Pitch ranking of the selected electrodes was attempted during first fitting; however, in some cases this was only possible at subsequent fitting sessions. After electrodes were balanced in loudness, participants were asked to name the electrodes with the highest and lowest pitches. Successive repetition and reordering led to a tonotopic ranking of the electrodes.

Follow-up assessment took place at 1, 3, 6 and 12 months postactivation. During follow-up, individual electrode stimulation for loudness, pitch and nonauditory side effects, and speech and sound perception were used to optimize the program. The nature and subjective strength of nonauditory side effects determined which electrode contacts were activated in this study. Contacts were either checked repeatedly with regard to nonauditory side effects at follow-up or were in some instances, depending upon the nature of nonauditory side effects, deactivated pending a shift from nonauditory to auditory sensations that required the activation of those electrodes. Some nonauditory side effects often decreased in magnitude over time and, despite being associated with negative side effects initially, could be reactivated at a later session. Side effects that left the electrodes completely unusable were typically located in the leg, arm, chest or face and described as pain, tickling or muscle activation; these were left deactivated.

\section{Audiological Testing}

For testing, subjects were seated in a sound-attenuated chamber, $1 \mathrm{~m}$ in front of a speaker. Recognition of environmental sounds was tested using the recorded test materials of the Sound Effects Recognition Test (SERT). This test consists of 3 different lists of 10 items each, which were offered in a closed-set procedure.

Speech test materials were presented in live voice at normal speech level. The order of the test conditions were auditory-visual (ABI + lip-reading), auditory only (ABI) and visual only (lip-reading). The auditoryonly condition was also presented in live voice, but the speaker's mouth was covered using a sound-transparent mask.

To acknowledge the large variability in hearing performance, 2 tests with different levels of difficulty were conducted: the Monosyllable-Trochee-Polysyllable (MTP) test from the MED-EL EARS test battery (http://www.medel.com/data/downloads/BRIDGE/Brochures/Ears-Norms-Manual.pdf) and an open-set sentence test. The MTP assesses words and number of syllables recognized and consists of a closed set of 12 words offered twice each in a random order. The open-set sentence tests employed were as follows: (1) the Hochmair-Schulz-Moser (Germany, $n=16$ ); (2) the Polish Hochmair-Schulz-Moser (Poland, $n=2$ ); (3) the Technical Committee on Cochlear Implant in Japan test, 2004 (Japan, n =6); (4) the open-set sentence recognition test (Hong Kong, $n=1$ ), and (5) the Institute of Hearing Research sentence test (South Africa, $n=1$ ). At each test interval, and for each of the 3 test conditions, a different list of sentences was used and the number of words recognized correctly counted. 
Subjective Benefit Assessment

Six months after first fitting all participants were asked to complete a questionnaire specifically designed to assess the subjective impact of the $\mathrm{ABI}$ on the users. The questionnaire consisted of 7 questions assessing topics such as the time needed to become accustomed to the ABI, the influence of the ABI on daily life and listening capacity, as well as the subject's overall impression regarding the ABI.

Statistical Analyses

Descriptive statistics were used to report demographic data and baseline device fitting characteristics. Quantitative data are presented as mean, standard deviation and range (minimum and maximum); qualitative data are presented as absolute and relative frequencies. The Kolmogorov-Smirnov test was used to determine data distribution.

The effects between first fitting and 12-month testing for the SERT, the closed-set MTP test and the open-set sentence test were examined using the nonparametric Mann-Whitney U test. To show the benefit over lip-reading added by the ABI, the auditory gain for open-set sentence test results was calculated by subtracting the mean scores obtained under visual-only conditions from those under auditory-visual conditions.

Outcomes of the 7-item subjective questionnaire are presented as absolute and relative frequencies. Missing data were not replaced but treated as 'missing' values. Data of participating study sites were pooled. To prevent a treatment-by-center interaction, each study site followed an agreed protocol. A p value $<0.05$ was determined as statistically significant. IBM SPSS Statistics 19 (IBM, Armonk, N.Y., USA) was used for all analyses. Graphs were created in Microsoft Office Excel 2010 (http://www.microsoft.com).

\section{Results}

Number of Active Electrodes and Nonauditory Side Effects

At first fitting an average of $8.8 \pm 2.2$ out of 12 available contacts were activated to provide auditory stimuli to the subjects (table 1). None of the 27 subjects included had less than 5 active electrodes. Over time, the number of active electrodes remained essentially stable. Electrode contacts were deactivated due to several reasons: (1) contacts providing no sensation at all; (2) contacts causing unpleasant sound sensation (sound often described as faint, scratchy or persistent); (3) contacts with the same pitch rank (for optimized fitting); (4) contacts with mixed-auditory and nonauditory sensations (if nonauditory sensations were not tolerated by the subject), and (5) contacts with only nonauditory responses.

No information was available regarding nonauditory side effects for 7 subjects $(25.9 \%)$; 8 subjects (29.6\%) did not experience any nonauditory side effects. Of the remaining 12 subjects the body location and nonauditory sensation with the number of contacts (deactivated and active) causing the side effect are shown in figure 1 . The nature of the side effect(s) led to deactivation in 48 out of 144 total contacts (33.3\%); 11 out of 144 contacts (7.6\%) were maintained in an active state despite subjects experiencing nonauditory sensations. Amongst these, 2 contacts were deactivated after the first fitting, while 9 were active throughout the duration of the study.

\section{Sound Effect Recognition Test}

The SERT was performed by 26 subjects in total. As shown in figure 2, a steady increase in SERT scores averaged across all data available was observed up to the 6-month test interval. The improvement between the first fitting scores and the 12-month test were significant ( $p=0.009, \mathrm{n}=11$ subjects who performed the test at the first fitting and 12-month test interval).

\section{Monosyllabic-Trochee-Polysyllabic Tests}

The closed-set MTP test was performed by 27 subjects in total. The test was scored by correct identification of syllables and words under the auditory-only and auditory-visual 
Matthies et al.: Auditory Brainstem Implantation Improves Speech Recognition in Neurofibromatosis Type II Patients

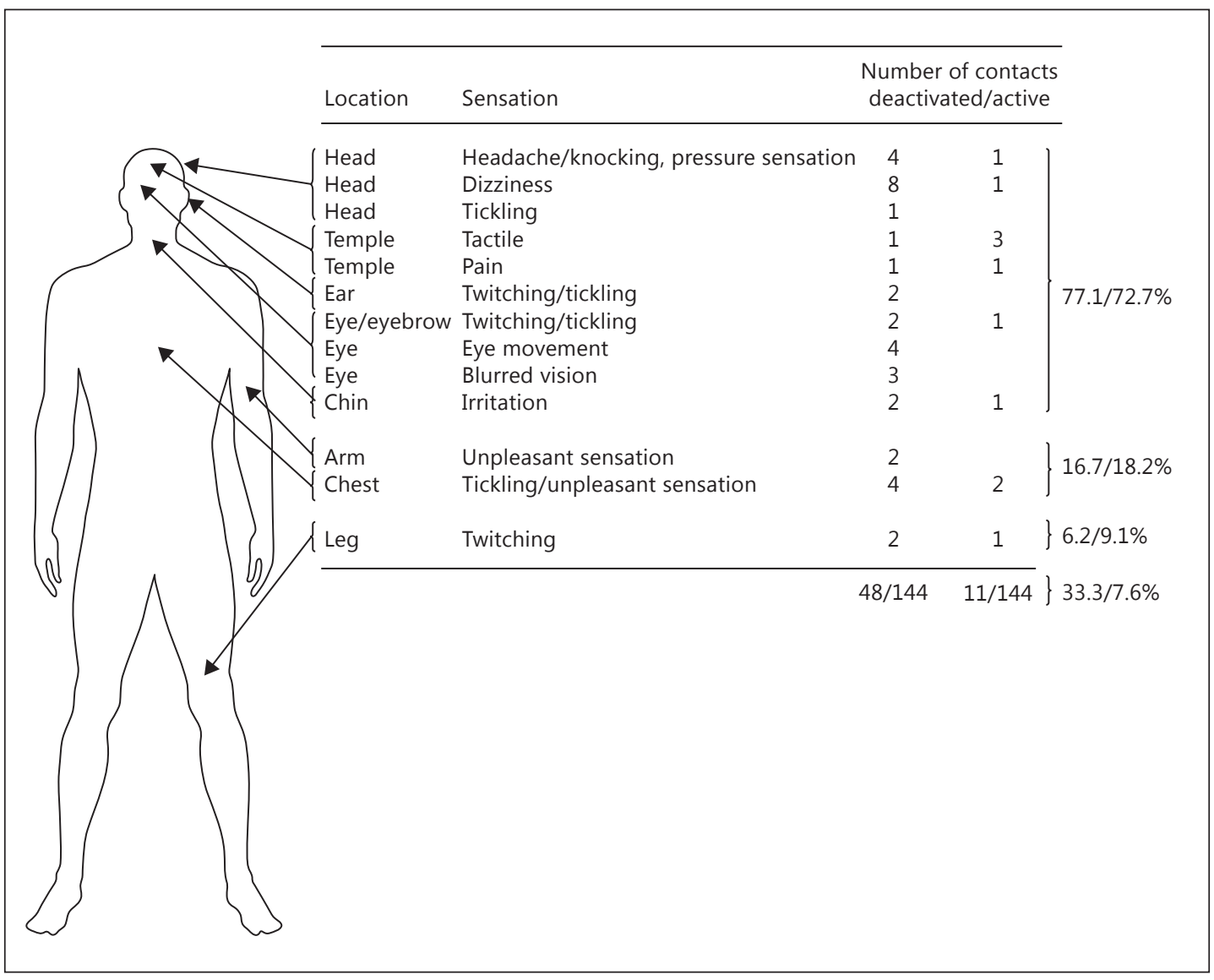

Fig. 1. Location and frequency of nonauditory sensations experienced by patients with an ABI at first fitting $(n=12)$.

condition. In both test conditions (auditory-only and auditory-visual) the mean syllable scores reached test ceiling immediately after device activation (data not shown). Individual word scores are shown in table 2.

Under auditory-only conditions the mean correct word score across all data available ('all data' group) was $11.7 \pm 6.4$ words out of $24(48.7 \%)$ at first fitting. The mean outcome calculated from patients who were tested at all scheduled intervals ('complete' group) was $12.1 \pm 6.0$ words $(50.4 \%)$. A steady increase in mean results was observed over the 12 -month follow-up period for both the 'all data' and the 'complete' group. The improvement between first fitting scores and 12-month testing was highly significant for auditory-only word recognition (Mann-Whitney U test: $\mathrm{p}<0.001, \mathrm{n}=19$ ).

Under the auditory-visual condition the test ceiling was reached at first fitting. Likewise, no statistically significant difference was observed in the auditory-visual word score between the first fitting and 12-month testing (Mann-Whitney $\mathrm{U}$ test: $\mathrm{p}=0.106, \mathrm{n}=18$ ).

\section{Sentence Tests}

Sentence tests were performed by 26 subjects in the auditory-visual condition, 23 in the auditory-only condition and 22 in the visual-only condition. Results averaged across all available data under all conditions are shown in figure 3. A highly significant improvement from the first fitting to the 12-month test was observed under the auditory-only (Mann- 
Matthies et al.: Auditory Brainstem Implantation Improves Speech Recognition in Neurofibromatosis Type II Patients

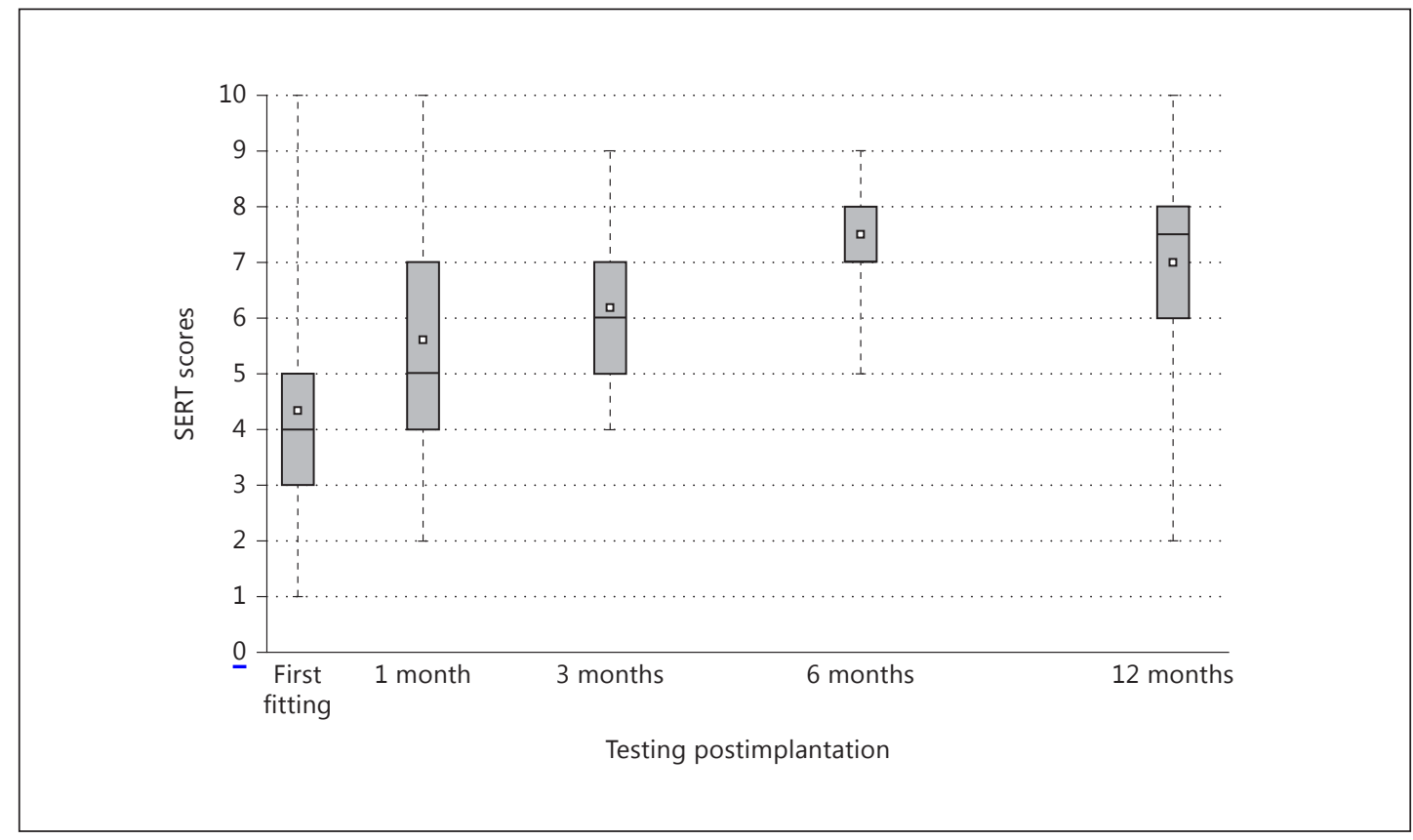

Fig. 2. Environmental sound recognition performance determined by SERT in patients with an ABI after first fitting and 1, 3, 6 and 12 months postactivation. Boxplot whiskers depict sample minimum and maximum; the white square equals the mean value.

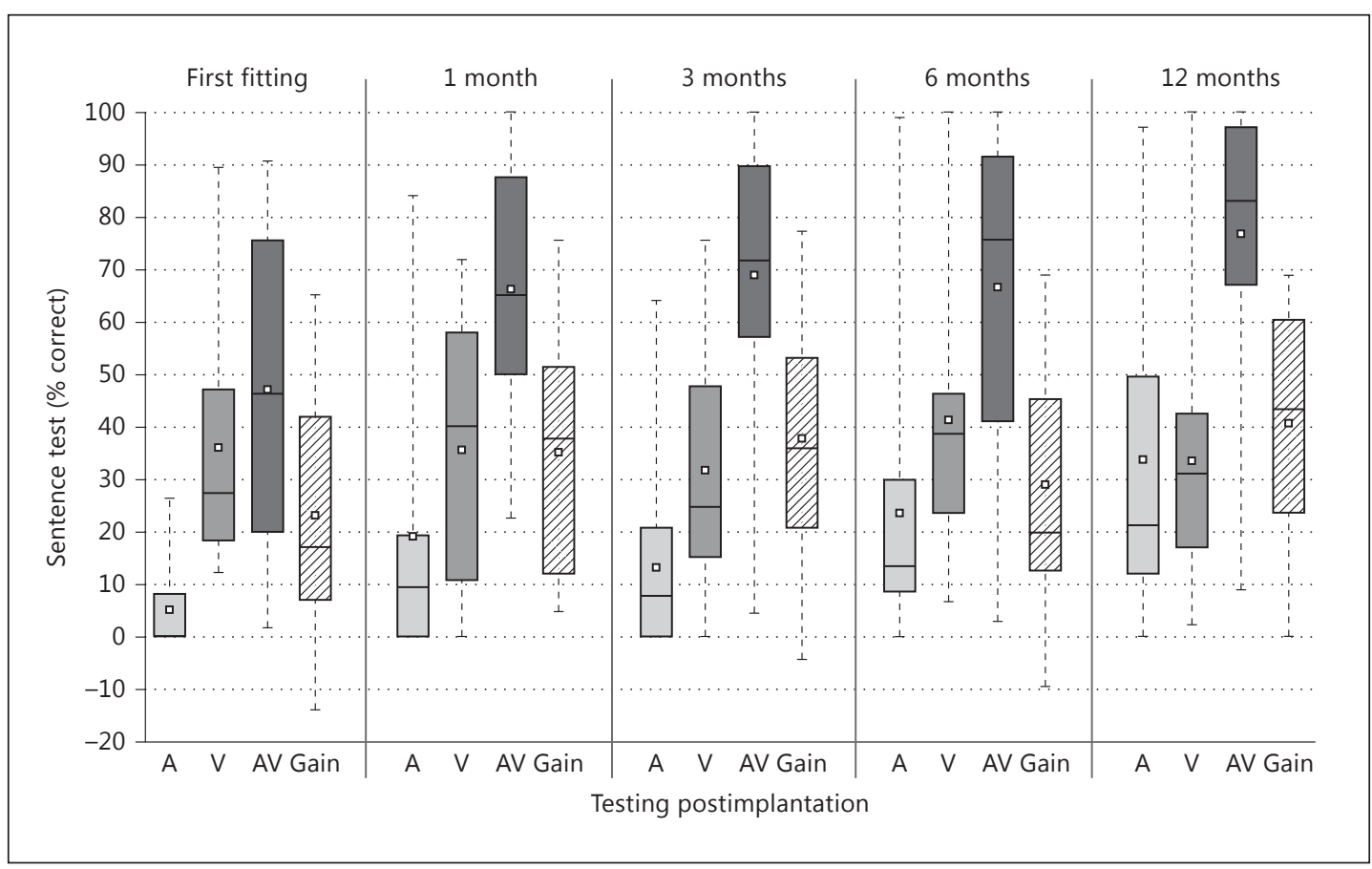

Fig. 3. Open-set speech recognition as determined by sentence testing in patients with an ABI after first fitting and 1, 3, 6 and 12 months postactivation. A: auditory only; V: visual only; AV: auditory-visual combined; Gain: AV-V. Boxplot whiskers depict sample minimum and maximum; the white square equals the mean value. Error bars represent standard deviation. Negative 'Gain' values represent patients who performed poorer in the combined auditory-only and visual-only conditions compared to the visual conditions. 
Matthies et al.: Auditory Brainstem Implantation Improves Speech Recognition in Neurofibromatosis Type II Patients

Table 2. Individual results of MTP words (words repeated correctly) of the auditory-only and auditory-visual test conditions

\begin{tabular}{|c|c|c|c|c|c|c|c|c|c|c|}
\hline \multirow{2}{*}{$\begin{array}{l}\text { Subject } \\
\text { ID }\end{array}$} & \multicolumn{5}{|c|}{ Auditory only } & \multicolumn{5}{|c|}{ Auditory-visual } \\
\hline & $\begin{array}{l}\text { first } \\
\text { fitting }\end{array}$ & $\begin{array}{l}1 \\
\text { month }\end{array}$ & $\begin{array}{l}3 \\
\text { months }\end{array}$ & $\begin{array}{l}6 \\
\text { months }\end{array}$ & $\begin{array}{l}12 \\
\text { months }\end{array}$ & $\begin{array}{l}\text { first } \\
\text { fitting }\end{array}$ & $\begin{array}{l}1 \\
\text { month }\end{array}$ & $\begin{array}{l}3 \\
\text { months }\end{array}$ & $\begin{array}{l}6 \\
\text { months }\end{array}$ & $\begin{array}{l}12 \\
\text { months }\end{array}$ \\
\hline 1 & - & 8 & 6 & - & 17 & - & 15 & 16 & - & 21 \\
\hline 2 & - & 14 & 22 & 16 & 22 & - & 23 & 24 & 24 & 24 \\
\hline 3 & 4 & - & 1 & 4 & 7 & 21 & - & 22 & 22 & 22 \\
\hline 4 & 13 & 21 & 20 & 22 & 21 & - & 24 & 23 & 24 & 24 \\
\hline 5 & - & - & 18 & 18 & 20 & - & - & 23 & 24 & 24 \\
\hline 7 & 20 & 24 & 24 & 24 & 23 & 24 & 24 & 24 & 24 & 24 \\
\hline 8 & 7 & 17 & 23 & 21 & 24 & 24 & 24 & 24 & 24 & 24 \\
\hline 10 & 12 & 14 & 21 & 24 & 24 & 24 & 24 & 24 & 24 & 24 \\
\hline 11 & - & - & - & 21 & 22 & - & - & - & 23 & 24 \\
\hline 12 & 14 & 21 & 19 & 21 & 21 & 22 & 23 & 24 & 24 & 24 \\
\hline 13 & 15 & 13 & 4 & 16 & 8 & 24 & 24 & 24 & 24 & 24 \\
\hline 14 & 14 & 20 & 18 & 24 & 20 & 24 & 24 & 24 & 24 & 24 \\
\hline 15 & 14 & 16 & 18 & 19 & 16 & 22 & 24 & 24 & 24 & 24 \\
\hline 16 & 6 & 22 & 13 & 17 & 21 & 24 & 22 & 23 & 24 & 21 \\
\hline 18 & 10 & 17 & 16 & 21 & 18 & 22 & 24 & 24 & 24 & 24 \\
\hline 20 & 0 & 12 & 10 & 15 & 20 & 24 & 24 & 24 & 24 & 24 \\
\hline 22 & 10 & 24 & 24 & - & - & 23 & 24 & 24 & - & - \\
\hline 23 & 6 & 9 & 19 & - & - & 24 & 24 & 24 & - & - \\
\hline 24 & 24 & 24 & - & 24 & 24 & 22 & 23 & - & 24 & 24 \\
\hline 25 & 11 & 4 & - & - & - & 24 & 24 & - & - & - \\
\hline 26 & 19 & 19 & 21 & 21 & 23 & 24 & 24 & 24 & 24 & 24 \\
\hline 27 & 11 & 12 & 18 & 22 & 22 & 24 & 24 & 24 & 24 & 24 \\
\hline 28 & 13 & 17 & 20 & 18 & 21 & 24 & 24 & 24 & 24 & 24 \\
\hline 29 & 18 & 16 & 18 & 20 & 23 & 23 & 23 & 23 & 24 & 24 \\
\hline $30^{1}$ & 19 & 15 & 16 & 16 & 12 & 24 & 24 & 24 & 24 & 24 \\
\hline $31^{1}$ & - & 20 & 19 & 16 & 21 & - & 24 & 24 & 24 & 24 \\
\hline 32 & 11 & 14 & 16 & 21 & 23 & 23 & 24 & 24 & 24 & 24 \\
\hline \multicolumn{11}{|l|}{ All data group } \\
\hline Mean \pm SD & $11.7 \pm 6.4$ & $15.4 \pm 5.3$ & $16.1 \pm 6.2$ & $17.9 \pm 4.8$ & $19.6 \pm 4.2$ & $23.2 \pm 1.0$ & $23.2 \pm 2.1$ & $23.2 \pm 2.1$ & $23.8 \pm 0.6$ & $23.6 \pm 1.0$ \\
\hline $\begin{array}{l}\text { Mean } \pm \text { SD } \\
\text { complete }\end{array}$ & $12.1 \pm 6.0$ & $15.8 \pm 3.0$ & $16.7 \pm 3.4$ & $18.8 \pm 2.4$ & $19.2 \pm 3.4$ & $23.4 \pm 0.8$ & $23.7 \pm 0.6$ & $23.8 \pm 0.4$ & $24.0 \pm 0.0$ & $23.8 \pm 0.8$ \\
\hline
\end{tabular}

Mean values \pm SD are depicted for all data available (all data) and for the patients who performed the test at all test intervals (complete) under auditory-only $(\mathrm{n}=17)$ and auditory-visual conditions $(\mathrm{n}=16)$. SD $=$ Standard deviation. ${ }^{1}$ Revision cases.

Whitney U test: $\mathrm{p}<0.001, \mathrm{n}=8$ ) and the auditory-visual test conditions ( $\mathrm{p}=0.001, \mathrm{n}=12)$; no significant improvement was observed under visual-only test conditions ( $p=0.083, n=6)$.

Individual sentence test results under the auditory-only and auditory-visual conditions are shown in table 3 . All subjects who performed the sentence test in the auditory-visual condition at first fitting (17 out of 26) were able to achieve at least some open-set speech understanding. Of the subjects available for the sentence test under auditory-visual conditions at first fitting and at 12-month testing, 11 out of 12 subjects performed better at the 12-month test interval. In the auditory-only condition 12 subjects performed the test at first fitting; 5 subjects achieved open-set speech understanding in this difficult test situation. After 12 months of ABI use 19 subjects could be tested, and all but 1 achieved open-set speech understanding. Overall, these data illustrate the improvement and learning ability over time 
Matthies et al.: Auditory Brainstem Implantation Improves Speech Recognition in Neurofibromatosis Type II Patients

Table 3. Individual sentence test results (\% correct) of the auditory-only and auditory-visual test conditions

\begin{tabular}{|c|c|c|c|c|c|c|c|c|c|c|}
\hline \multirow{2}{*}{$\begin{array}{l}\text { Subject } \\
\text { ID }\end{array}$} & \multicolumn{5}{|c|}{ Auditory only } & \multicolumn{5}{|c|}{ Auditory-visual } \\
\hline & $\begin{array}{l}\text { first } \\
\text { fitting }\end{array}$ & $\begin{array}{l}1 \\
\text { month }\end{array}$ & $\begin{array}{l}3 \\
\text { months }\end{array}$ & $\begin{array}{l}6 \\
\text { months }\end{array}$ & $\begin{array}{l}12 \\
\text { months }\end{array}$ & $\begin{array}{l}\text { first } \\
\text { fitting }\end{array}$ & $\begin{array}{l}1 \\
\text { month }\end{array}$ & $\begin{array}{l}3 \\
\text { months }\end{array}$ & $\begin{array}{l}6 \\
\text { months }\end{array}$ & $\begin{array}{l}12 \\
\text { months }\end{array}$ \\
\hline 1 & - & 0.0 & 0.0 & - & 35.6 & - & 50.0 & 4.4 & - & 8.9 \\
\hline 2 & - & 0.9 & 22.8 & 22.6 & 16.0 & - & 42.5 & 60.4 & 38.7 & 59.4 \\
\hline 3 & - & - & - & - & - & 1.8 & - & - & 8.8 & - \\
\hline 4 & 12.3 & 19.3 & 0.0 & 31.6 & 1.8 & 70.2 & 89.5 & 82.5 & 78.9 & 63.2 \\
\hline 5 & - & - & 25.0 & 35.7 & 21.2 & - & - & 26.8 & 48.2 & 21.2 \\
\hline 7 & 26.4 & 80.2 & 64.2 & 87.7 & 86.8 & 78.3 & 100.0 & 91.5 & 96.2 & 100.0 \\
\hline 8 & - & 15.1 & 12.3 & 28.3 & 63.4 & - & 34.0 & 69.8 & 91.5 & 98.1 \\
\hline 10 & 0.0 & 1.9 & 2.8 & 68.3 & 81.1 & 46.2 & 63.2 & 83.0 & 92.5 & 98.1 \\
\hline 11 & - & - & - & 69.8 & 79.2 & - & - & - & 100.0 & 100.0 \\
\hline 12 & - & - & 8.3 & 13.3 & 23.3 & - & 75.0 & 81.7 & 75.0 & 93.3 \\
\hline 13 & - & - & - & - & - & 44.3 & 40.6 & 43.4 & 59.4 & - \\
\hline 14 & 6.6 & 28.3 & 12.3 & 12.3 & - & 78.3 & 79.2 & 94.3 & 91.5 & 97.2 \\
\hline 16 & - & - & - & 0.0 & 10.4 & 5.1 & - & - & 2.8 & 67.0 \\
\hline 18 & - & 1.7 & 18.3 & 13.3 & 11.7 & 30.0 & 56.7 & 71.7 & 65.0 & 80.0 \\
\hline 20 & - & - & - & - & - & - & 65.1 & - & 65.1 & 83.0 \\
\hline 22 & 0.0 & 94.3 & - & - & 86.8 & 91.5 & 100.0 & - & - & - \\
\hline 23 & 0.0 & 0.0 & 7.0 & - & - & 75.4 & 87.7 & 96.5 & - & - \\
\hline 24 & 3.8 & 65.1 & - & 99.1 & 97.2 & 90.6 & 94.3 & - & 98.1 & 100.0 \\
\hline 25 & 0.0 & - & - & - & - & 15.8 & - & - & - & - \\
\hline 26 & 13.2 & 9.4 & 39.6 & 9.4 & 12.3 & 70.8 & 90.6 & 100.0 & 100.0 & 79.2 \\
\hline 27 & - & 9.6 & 3.8 & 7.5 & 14.2 & - & 65.1 & 87.7 & 91.5 & 87.7 \\
\hline 28 & - & - & 0.0 & 1.9 & 16.0 & 2.8 & 23.8 & 35.8 & 28.3 & 75.5 \\
\hline 29 & 0.0 & 0.0 & 0.0 & 0.0 & 5.7 & 19.8 & 29.2 & 56.6 & 37.7 & 73.6 \\
\hline $30^{1}$ & 0.0 & 1.9 & 0.0 & 0.0 & 0.0 & 35.8 & 52.8 & 57.5 & 35.8 & 48.1 \\
\hline $31^{1}$ & - & 0.0 & 22.6 & 11.3 & 38.7 & - & 82.1 & 92.5 & 76.4 & 84.9 \\
\hline 32 & 0.0 & 0.0 & 0.0 & 11.3 & 36.8 & 53.8 & 69.8 & 70.8 & 84.0 & 93.4 \\
\hline \multicolumn{11}{|c|}{ All data group } \\
\hline $\mathrm{n}$ & 12 & 17 & 18 & 19 & 20 & 17 & 21 & 19 & 22 & 21 \\
\hline Mean \pm SD & $5.2 \pm 8.3$ & $19.9 \pm 30.2$ & $13.3 \pm 17.1$ & $27.6 \pm 30.8$ & $36.9 \pm 32.8$ & $47.7 \pm 31.3$ & $66.2 \pm 23.6$ & $68.8 \pm 26.2$ & $66.6 \pm 30.1$ & $76.8 \pm 25.3$ \\
\hline $\begin{array}{l}\text { Mean } \pm \text { SD } \\
\text { complete }\end{array}$ & $7.4 \pm 10$. & $16.1 \pm 29.1$ & $15.2 \pm 26.0$ & $29.8 \pm 35.0$ & $32.1 \pm 37.6$ & $48.6 \pm 26.2$ & $65.5 \pm 25.6$ & $74.4 \pm 20.0$ & $71.0 \pm 27.5$ & $80.8 \pm 16.9$ \\
\hline
\end{tabular}

Mean values \pm SD are depicted for all data and for the patients who performed the test at all test intervals (complete) under auditoryonly $(n=7)$ and auditory-visual conditions $(n=10)$. SD $=$ Standard deviation. ${ }^{1}$ Revision cases.

both on an individual and group basis. In summary, of the 19 subjects that could be tested at 12 months, under auditory-only conditions, a mean open speech perception of $37 \%$ was achieved. Under audio-visual conditions at 12 months the percentage of speech perception achieved was $77 \%$.

To determine the benefit of ABI use over lip-reading alone, the auditory gain was calculated for the 'all data' group (fig. 3). At all test intervals the auditory gain was greater than the auditory-only performance, i.e. the sum of the results under auditory-only and visual-only combined was less than the performance under auditory-visual conditions. Furthermore, the auditory gain increased significantly over time from the first fitting to the 12-month test $(\mathrm{p}=$ 0.008). 
Matthies et al.: Auditory Brainstem Implantation Improves Speech Recognition in Neurofibromatosis Type II Patients

Table 4. Questionnaire results

\begin{tabular}{|c|c|c|c|}
\hline & & $\mathrm{n}$ & $\%$ \\
\hline \multirow{5}{*}{$\begin{array}{l}\text { About how long would you say it took for you to } \\
\text { adjust to your ABI? }\end{array}$} & no time & 3 & 21.4 \\
\hline & hardly any time & 3 & 21.4 \\
\hline & moderate amount of time & 5 & 35.7 \\
\hline & quite some time & 3 & 21.4 \\
\hline & a very long time & 0 & 0.0 \\
\hline \multirow[t]{5}{*}{ How difficult was this adjustment for you? } & not difficult & 4 & 26.7 \\
\hline & somewhat difficult & 7 & 46.6 \\
\hline & moderately difficult & 2 & 13.3 \\
\hline & quite difficult & 1 & 6.7 \\
\hline & very difficult & 1 & 6.7 \\
\hline \multirow{5}{*}{$\begin{array}{l}\text { How would you rate the changes in your emotional } \\
\text { state since you began wearing an ABI? }\end{array}$} & very positive & 4 & 25.0 \\
\hline & somewhat positive & 4 & 25.0 \\
\hline & neutral & 7 & 43.7 \\
\hline & somewhat negative & 1 & 6.3 \\
\hline & very negative & 0 & 0.0 \\
\hline \multirow{5}{*}{$\begin{array}{l}\text { Has your ABI improved listening in individual } \\
\text { conversation? }\end{array}$} & not at all & 0 & 0.0 \\
\hline & hardly & 1 & 6.3 \\
\hline & sometimes & 6 & 37.5 \\
\hline & often & 9 & 56.2 \\
\hline & not applicable & 0 & 0.0 \\
\hline \multirow[t]{5}{*}{ Has your ABI improved listening in groups? } & not at all & 2 & 12.5 \\
\hline & hardly & 5 & 31.3 \\
\hline & sometimes & 6 & 37.5 \\
\hline & often & 2 & 12.5 \\
\hline & not applicable & 1 & 6.3 \\
\hline \multirow{5}{*}{$\begin{array}{l}\text { Has your ABI improved listening in noisy } \\
\text { environments? }\end{array}$} & not at all & 4 & 26.7 \\
\hline & hardly & 6 & 40.0 \\
\hline & sometimes & 3 & 20.0 \\
\hline & often & 1 & 6.7 \\
\hline & not applicable & 1 & 6.7 \\
\hline \multirow[t]{5}{*}{ How satisfied are you in general with your ABI? } & very satisfied & 5 & 33.3 \\
\hline & fairly satisfied & 6 & 40.0 \\
\hline & adequately satisfied & 4 & 26.7 \\
\hline & hardly satisfied & 0 & 0.0 \\
\hline & not at all satisfied & 0 & 0.0 \\
\hline
\end{tabular}

\section{Subjective Questionnaire}

The subjective questionnaire was completed by 16 out of 27 subjects (table 4). Adjustment to the ABI was performed without difficulty in the majority of cases. The time needed to adjust to the ABI was 'minimal' or 'moderate' in $78.5 \%$ of the subjects. Accordingly, $73.3 \%$ reported that the adjustment to the ABI was 'not at all' or only 'somewhat' difficult for them. Only 1 subject (6.7\%) felt that the adjustment was 'very difficult'; $50 \%$ of the subjects experienced 'very positive' or 'somewhat positive' changes in their emotional state since wearing the ABI. Again, only 1 subject (6.3\%) reported a 'somewhat negative' experience. Ratings given by the users of the degree of help provided by the ABI in different listening situations showed the biggest benefit during individual conversation, with $93.7 \%$ of patients reporting improved listening abilities 'sometimes' to 'often'. Listening in groups was 'sometimes' to 'often' improved in $50.0 \%$ of users; however, $43.8 \%$ reported that they 'hardly' or 'not at all' bene- 
fitted from the $\mathrm{ABI}$ during group conversation. The least benefit was experienced in noisy environments with only $26.7 \%$ of users reporting a benefit 'sometimes' to 'often' and $66.7 \%$ benefitting 'hardly' or 'not at all'. The questionnaire shows that, overall, $100 \%$ of patients were 'adequately satisfied' to 'very satisfied' with their ABI.

\section{Discussion}

In patients suffering from NF2 and a complete hearing loss, following tumor growth or removal, use of an ABI affords them some external auditory information. The extent of information provided is thought to facilitate lip-reading and the recognition of environmental sounds $[9,16-19,22]$. However, significant functional auditory-alone speech recognition is not expected [30-32]. Despite these limitations, NF2 patients with an ABI report varying degrees of benefit $[22,33-37]$. The data presented herein shows that patients with an ABI demonstrate an initial improvement in SERT following first fitting. Likewise, MTP results show that under auditory-only conditions identification of words is enhanced with an ABI. Similarly, the capacity of the patients to determine sentences under auditory-only conditions was improved. This effect was apparent as early as 1 month after fitting. Sentence test performance under auditory-visual conditions was improved significantly. However, as no significant improvement in visual-only sentence testing was observed, the data in the present study suggests that NF2 patients can acquire benefits beyond enhanced lip-reading when using an ABI. This is likely to contribute to the patient's perception of the subjective benefits of using an ABI.

A period of acclimatization and learning facilitates the achievement of maximum benefit $[9,35]$. However, the effects of NF2 on general health also need to be considered. In the present study follow-up testing was frequently interrupted or abandoned on account of patients suffering fatigue or on account of extrinsic factors as described by Otto et al. [9]. As follow-up is often perturbed by the pathological presentation of NF2, data were analyzed as a complete data set or following the exclusion of any individual(s) with missing data. Visual comparison of both data sets indicates that there is no apparent difference between the 'healthier' group and the group as a whole.

Another health-related consequence of ABI fitting is that electrical stimulation of the human brainstem carries the risk of nonauditory side effects. Most ABI patients experience these side effects, the solution to which is simply turning the electrode off [23]. Likewise, postoperative side effects of $\mathrm{ABI}$ activation determined the number of stimulatory electrodes programmed in this study. However, successful programming around the nonauditory sensations was possible in all patients included. The total number of active electrodes had no significant effect on the overall exceptional hearing performance of NF2 patients with an ABI presented in this study (data not shown) and the number of active electrodes over time appeared stable compared to the setting at first fitting. Similarly, Schmidt Goffi-Gomez et al. [38] showed that the number of active electrodes was not clinically related to outcome.

The current data clearly illustrate that with an ABI high levels of auditory performance were achieved in NF2 patients. NF2 patients with complete hearing loss implanted with the MED-EL COMBI 40+ or ABI showed an improvement in hearing performance after surgery. Closed-set MTP testing indicated that between the first fitting and the 12-month follow-up auditory-only word recognition was improved.

Of greater importance in the present study, NF2 patients with an ABI showed a significant improvement in auditory recognition when tested in an open-set task, i.e. sentence tests. The capacity of the patients to recognize sentences under auditory-only conditions over the entire test period (from first fitting to 12-month follow-up) improved and, likewise, their sentence 
test performance under auditory-visual conditions. The improvement in sentence recognition was already apparent after 1 month. These data are of significant relevance because typically under auditory-only conditions ABI listeners are unable to recognize a significant amount of speech when tested in an open-set recognition task [13]. Using sound only from their ABI few NF2 patients recognized up to $20 \%$ of the words in sentences $[13,15]$. The majority of NF2 patients recognize less than $5 \%$ of the words in sentences, even after several years of practice with the ABI $[13,39]$. Moreover, as test materials become more complex, e.g. from word tests to open-set testing, performance with the $\mathrm{ABI}$ is thought to decline, especially under auditory-only conditions [17]. Nevison et al. indicate that although closed-set word identification tests show limited auditory-alone word identification, it would not be possible for $\mathrm{ABI}$ users to rely on their $\mathrm{ABI}$ alone. It was thought that the use of the ABI with lip-reading allowed the key words in conversation to be identified [17]. In contrast, the data presented in this study shows clearly that a large proportion of ABI users achieve valuable open-set speech understanding even if they rely exclusively on auditory-only input. Of all patients tested (all data) in the present study, the percentage of words recognized correctly in the sentence test using auditory-only cues was $20 \%$ after 1 month of ABI use. At the 12 -month test interval this increased to $37 \%$, which accounts for a considerably larger proportion than reported previously in the published literature $[13,39]$. To investigate possible influencing factors comparative studies with a larger cohort of patients would be necessary. The current data is, however, substantiated with preliminary data collected in 2002 on the MED-EL ABI [22]. Furthermore, the results obtained with lip-reading in conjunction with the auditory input improved the benefit further than under auditory-only conditions. Thus, the data suggests that the exceptional benefit of the COMBI $40+$ or ABI is in terms of comparatively real-life communication. The reasons for the difference in speech outcomes in the present study, compared to other published studies, have yet to be determined. We suspect the placing electrode used in MED-EL ABI systems has an effect. Once the placing electrode has been positioned intraoperatively, electrically evoked auditory brainstem responses can be recorded that aid the surgeon in the correct placement of the active ABI electrode. We presume that the test stimulation and intraoperative recording of electric auditory brainstem response may be one reason for better results using the MED-EL ABI. This should be a major point of investigation in future studies.

Moreover, the auditory gain as determined by open-set testing increased over time and was significantly greater after 12 months compared to the results at activation $(p=0.008)$. This suggests that the gain in speech recognition by NF2 patients with an ABI will potentially improve further over time. This is likely to occur due to a continued learning effect following ABI activation. Likewise, several authors indicate that the success of the NF2 patients with hearing loss in rehabilitation is most obvious upon long-term follow-up [20,40].

However, some patients with an ABI in the present study showed a complete lack of improvement, whilst others managed a significant degree of rehabilitation. Other authors also report a significant degree of interindividual variability in the performance of NF2 patients with an ABI [13, 19]. Similarly, the study by Nevison et al. [17] in 2002 indicated that although most subjects did not achieve satisfactory auditory-alone open-set speech understanding, 2 patients of 17 tested received sufficient benefit from the ABI to an extent that allowed them to participate in conversation without the visual cues of lip-reading. The wide variation may in part be contributed to difficulties with follow-up, as mentioned briefly earlier. Frequently, the follow-up of patients with NF2 is perturbed due to changes in the status of the patient's health; in addition to nonauditory side effects, the most common of which are dizziness and ipsilateral tingling [41-43].

Despite these difficulties, the subjective benefits in patients with an ABI determined via questionnaire in the present study showed that overall all of the respondents were 'adequately' 
Matthies et al.: Auditory Brainstem Implantation Improves Speech Recognition in Neurofibromatosis Type II Patients

to 'very satisfied' with their ABI even after 6 months of follow-up. The majority reported improved listening ability 'sometimes' to 'often' in individual conversations. However, listening in noisy environments continued to pose a problem, as a case study of ABI use had previously indicated [20]. Similarly, listening in groups was 'sometimes' to 'not at all' improved in most cases. According to Colletti et al. [41], perceptual performance in ABI recipients can often vary considerably depending on the duration of the disease, the treatment of the disease and the number of active electrodes, in addition to their spatial configuration. However, in the context of the present study the data illustrates a relatively consistent improvement following auditory brainstem implantation with an overall satisfaction from 'adequately' to 'very satisfied', demonstrating the importance of providing some auditory input to patients deafened due to NF2.

In conclusion, the data presented herein indicate that NF2 patients with an ABI generally show improved closed-set speech recognition and, moreover, that patients show exceptional open-set sentence recognition. The acquisition of open-set speech recognition goes beyond the benefits achieved by lip-reading alone. Taking this into account and the young age of most NF2 sufferers, in addition to the unfortunate progressiveness of the disease, the capacity to restore some of the patient's hearing is of significant relevance, particularly in terms of quality of life.

\section{References}

1 Hanemann CO: Magic but treatable? Tumours due to loss of merlin. Brain 2008;131:606-615.

- 2 Evans DG, Moran A, King A, Saeed S, Gurusinghe N, Ramsden R: Incidence of vestibular schwannoma and neurofibromatosis 2 in the North West of England over a 10-year period: higher incidence than previously thought. Otol Neurotol 2005;26:93-97.

- 3 Samii M, Matthies C: Management of vestibular schwannomas. Hearing function in 1,000 cases. Neurosurgery 1997;40:248-262.

- 4 Samii M, Gerganov V, Samii A: Improved preservation of hearing and facial nerve function in vestibular schwannoma surgery via the retrosigmoid approach in a series of 200 patients. Neurosurgery 2006;105: 527-535.

- 5 Sughrue ME, Kaur R, Rutkowski MJ, et al: A critical evaluation of vestibular schwannoma surgery for patients younger than 40 years of age. Neurosurgery 2010;67:1646-1654.

6 Tringali S, Ferber-Viart C, Fuchsmann C, Buiret G, Zaouche S, Dubreuil C: Hearing preservation in retrosigmoid approach of small vestibular schwannomas: prognostic value of the degree of internal auditory canal filing. Otol Neurotol 2010;31:1469-1472.

- 7 Tran Ba Huy P, Kania R, Frachet B, Poncet C, Legac MS: Auditory rehabilitation with cochlear implantation in patients with neurofibromatosis type 2. Acta Otolaryngol 2009;129:971-975.

- 8 Vincenti V, Pasanisi E, Guida M, Di Trapani G, Sanna M: Hearing rehabilitation in neurofibromatosis type 2 patients: cochlear versus auditory brainstem implantation. Audiol Neurotol 2008;13:273-280.

- 9 Otto SR, Brackmann DE, Hitselberger WE, Shannon RV, Kuchta J: Multichannel auditory brainstem implant: update on performance in 61 patients. J Neurosurg 2002;96:1063-1071.

$\checkmark 10$ Brackmann DE, Hitselberger WE, Nelson RA, et al: Auditory brainstem implant. I. Issues in surgical implantation. Otolaryngol Head Neck Surg 1993;108:624-633.

$\checkmark 11$ Edgerton BJ, House WF, Hitselberger WE: Hearing by cochlear nucleus stimulation in humans. Ann Otol Rhinol Laryngol Suppl 1982;91:117-124.

12 Shannon RV, Fayad J, Moore J, et al: Auditory brainstem implant. II. Post-surgical issues and performance. Otolaryngol Head Neck Surg 1993;108:634-642.

13 Colletti V, Shannon RV, Carner M, Veronese S, Colletti L: Progress in restoration of hearing with the auditory brainstem implant. Prog Brain Res 2009;175:333-345.

14 Skarzynski H, Behr R, Lorens A, Podskarbi-Fayette R, Kochanek K: Bilateral electric stimulation from auditory brainstem implants in a patient with neurofibromatosis type 2. Med Sci Monit 2009;15:CS100-CS104.

15 Sollmann WP, Laszig R, Marangos N, et al: Electrical stimulation of the cochlear nucleus. First results of the European auditory brainstem implant clinical trial. 11th International Congress of Neurological Surgery, Amsterdam, 1997.

16 Matthies C, Thomas S, Moshrefi M, et al: Auditory brainstem implants: current neurosurgical experiences and perspective. J Laryngol Otol Suppl 2000;114:32-36. 
Matthies et al.: Auditory Brainstem Implantation Improves Speech Recognition in Neurofibromatosis Type II Patients

17 Nevison B, Laszig R, Sollmann WP, et al: Results from a European clinical investigation of the nucleus multichannel auditory brainstem implant. Ear Hear 2002;23:170-183.

18 Behr R, Müller J, Shehata-Dieler W, et al: The high rate CIS auditory brainstem implant for restoration of hearing in NF2 patients. Skull Base 2007;17:91-107.

19 Grayeli AB, Kalamarides M, Bouccara D, Ambert-Dahan E, Sterkers O: Auditory brainstem implant in neurofibromatosis type 2 and non-neurofibromatosis type 2 patients. Otol Neurotol 2008;29:1140-1146.

20 Maini S, Cohen MA, Hollow R, Briggs R: Update on long-term results with auditory brainstem implants in NF2 patients. Cochlear Implants Int 2009;10:33-37.

-21 Neff BA, Wiet RM, Lasak JM, et al: Cochlear implantation in the neurofibromatosis type 2 patient: long-term follow-up. Laryngoscope 2007;117:1069-1072.

-22 Jackson KB, Mark G, Helms J, Mueller J, Behr R: An auditory brainstem implant system. Am J Audiol 2002;11: 128-133.

23 Shannon RV: Threshold functions for electrical stimulation of the human cochlear nucleus; in Kent RD (ed): The MIT Encyclopedia of Communication Disorders. Massachusetts, MIT Press, 2004, vol 40, pp 427-429.

24 Otto SR, Shannon RV, Brackmann DE, Hitselberger WE, Staller S, Menapace C: The multichannel auditory brain stem implant: performance in twenty patients. Otolaryngol Head Neck Surg 1998;118:291-303.

25 Vincent C, Zini C, Gandolfi A, et al: Results of the MXM Digisonic auditory brainstem implant clinical trials in Europe. Otol Neurotol 2002;23:56-60.

26 Fayad JN, Otto SR, Brackmann DE; in Møller AR (ed): Cochlear and Brainstem Implants. Basel, Karger, 2006, vol 64, pp 144-153.

27 St. Clair EG, Golfinos JG, Roland JT: Auditory brainstem implants; in Waltzmann SB, Roland JT (eds): Cochlear Implants. New York, Thieme, 2006, pp 222-229.

28 Kuchta J, Otto SR, Shannon RV, Hitselberger WE, Brackmann DE: The multichannel auditory brainstem implant: how many electrodes make sense? J Neurosurg 2004;100:16-23.

29 Wilson BS, Finley CC, Lawson DT, Wolford RD, Eddington DK, Rabinowitz WM: Better speech recognition with cochlear implants. Nature 1991;352:236-238.

-30 Laszig R, Aschendorff A: Cochlear implants and electrical brainstem stimulation in sensorineural hearing loss. Curr Opin Neurol 1999;12:41-44.

-31 Ebinger K, Otto S, Arcaroli J, Staller S, Arndt P: Multichannel auditory brainstem implant: US clinical trial results. J Laryngol Otol 2000;114(suppl 27):50-53.

32 Toh EH, Luxford WM: Cochlear and brainstem implantation. Otolaryngol Clin North Am 2002;35:325-342.

-33 Lustig LR, Yeagle J, Driscoll CLW, Blevins N, Francis H, Niparko J: Cochlear implantation in patients with neurofibromatosis type 2 and bilateral vestibular schwannoma. Otol Neurotol 2006;27:512-518.

$\$ 34$ Colletti V: Auditory outcomes in tumor vs. nontumor patients fitted with auditory brainstem implants. Adv Otorhinolaryngol 2006;64:167-185.

-35 Lenarz M, Matthies C, Lesinski-Schiedat A, et al: Auditory brainstem implant. Part II. Subjective assessment of functional outcome. Otol Neurotol 2002;23:694-697.

-36 Lenarz T, Moshrefi M, Matthies C, et al: Auditory brainstem implant. Part I. Auditory performance and its evolution over time. Otol Neurotol 2001;22:823-833.

37 Sanna M, Di Lella F, Guida M, Merkus P: Auditory brainstem implants in NF2 patients: results and review of the literature. Otol Neurotol 2012;33:154-164.

-38 Schmidt Goffi-Gomez MV, Megalhaes AT, Brito-Neto R, Tsuji RK, de Queiroz Telles Gomes M, Ferreira Bento R: Auditory brainstem implant outcomes and MAP parameters: report of experiences in adults and children. Int J Pediatr Otorhinolaryngol 2012;76:257-264.

-39 Schwartz MS, Otto SR, Shannon RV, Hitselberger WE, Brackmann DE: Auditory brainstem implants. Neurotherapeutics 2008;5:128-136.

40 Lesinski-Schiedat A, Frohne C, Illg A, et al: Auditory brainstem implant in auditory rehabilitation of patients with neurofibromatosis type 2: Hannover program. J Laryngol Otol 2000;114:15-17.

-41 Colletti V, Carner M, Miorelli V, Guida M, Colletti L, Fiorino F: Auditory brainstem implant (ABI): new frontiers in adults and children. Otolaryngol Head Neck Surg 2005;133:126-138.

-42 Otto SR, Brackmann DE, Hitselberger WE, Shannon RV: Brainstem electronic implants for bilateral anacusis following surgical removal of cerebello-pontine angle lesions. Otolaryngol Clin North Am 2001;34:485-499.

-43 Otto SR, Brackmann DE, Hitselberger WE: Auditory brainstem implantation in 12- to 18-year olds. Arch Otolaryngol Head Neck Surg 2004;130:656-659. 